\title{
PENENTUAN CADANGAN PREMI UNTUK ASURANSI JOINT LIFE
}

\author{
Ni Luh Putu Ratna Dewi ${ }^{\S 1}$, I Nyoman Widana ${ }^{2}$, Desak Putu Eka Nilakusmawati ${ }^{3}$ \\ ${ }^{1}$ Jurusan Matematika Fakultas MIPA - Universitas Udayana [Email: ratnadewiputu@ gmail.com] \\ ${ }^{2}$ Jurusan Matematika Fakultas MIPA - Universitas Udayana [Email: nwidana@ yahoo.com] \\ ${ }^{3}$ Jurusan Matematika Fakultas MIPA - Universitas Udayana [Email: nilakusmawati@ unud.ac.id] \\ ${ }^{\S}$ Corresponding Author
}

\begin{abstract}
Premium reserve is a number of fund that need to be raised by insurance company in preparation for the payment of claims. This study aims to get the formula of premium reserve as well as the value of the premium reserve for joint life insurance by using retrospective calculation method. Joint life insurance participants in this study are limited to 2 people. Calculations in this study is using Indonesian Mortality Table (TMI) 2011, joint life mortality tables, commutation tables, value of annuities, value of single premiums and constant annual premium and using constant interest rates of $5 \%$. The results showed that by using age of the participant insurance joint life of $x=50$ and $y=45$ years and the premium payment period of $t=10$ years, we obtained that the value of premium reserve from the end of the first year until the end of the 11th year has increased every year, while the value of premium reserves from the end of the 12th year and so on until a lifetime has decreased every year.
\end{abstract}

Keywords: Joint Life Insurance, Premium Reserve, Retrospective

\section{PENDAHULUAN}

Asuransi jiwa dilihat dari jumlah tertanggungnya dapat dibagi menjadi dua yaitu asuransi jiwa tunggal dan asuransi jiwa gabungan. Asuransi jiwa gabungan salah satunya adalah asuransi joint life. Asuransi joint life merupakan asuransi yang menanggung dua jiwa atau lebih dalam satu polis asuransi.

Dalam asuransi jiwa, tertanggung akan diberikan sejumlah uang yang disebut santunan atau uang pertanggungan yang akan diberikan oleh perusahaan asuransi. Tertanggung juga mempunyai kewajiban kepada perusahaan asuransi jiwa untuk membayar premi.

Premi yang telah terkumpul di perusahaan asuransi jiwa nantinya akan digunakan oleh perusahaan asuransi jiwa untuk membayar uang pertanggungan. Dalam jangka waktu tertentu, pendapatan yang diperoleh perusahaan asuransi dari premi beserta bunganya biasanya akan jauh lebih besar dari jumlah uang pertanggungan yang harus dibayarkan oleh perusahaan asuransi kepada pihak tertanggung. Kelebihan dana inilah yang kemudian disimpan sebagai cadangan premi.

Cadangan premi ini nantinya akan digunakan untuk membayar uang pertanggungan apabila terjadi klaim dan premi tidak mencukupi untuk membayar uang pertanggungan tersebut sehingga perusahaan asuransi tidak kesulitan untuk membayarnya.

Menurut Destriani \& Mara [2], perusahaan asuransi jiwa tidak sedikit yang mengalami kerugian yang disebabkan karena perusahaan tersebut tidak tepat dalam mengatur cadangan preminya. Akibatnya, perusahaan asuransi tidak mampu membayar uang pertanggungan kepada pihak tertanggung ketika jumlah klaim yang diajukan pihak tertanggung ternyata melebihi jumlah klaim yang telah diprediksi sebelumnya. Keadaan ini dapat diantisipasi jika perusahaan asuransi jiwa memiliki dana cadangan premi yang telah disiapkan dan dihitung dengan tepat.

Salah satu metode perhitungan cadangan premi bersih adalah metode perhitungan secara retrospektif. Perhitungan secara retrospektif 
merupakan perhitungan cadangan premi berdasarkan jumlah total pendapatan di waktu yang lampau sampai dilakukan perhitungan cadangan, dikurangi dengan jumlah pengeluaran di waktu yang lampau (Futami [3]).

Pada penelitian ini, akan dicari formula cadangan premi bersih tahunan pada asuransi joint life dengan menggunakan metode perhitungan cadangan premi secara retrospektif, dan untuk perhitungan premi tahunan pada penelitian ini akan dihitung dengan menggunakan formula premi tahunan konstan untuk asuransi joint life yang telah diteliti oleh (Matvejevs \& Matvejevs [5]).

Peluang gabungan dari dua orang yang berusia $x$ dan $y$ tahun akan tetap hidup selama $t$ tahun dinotasikan dengan ${ }_{t} p_{x y}$ dirumuskan sebagai berikut:

$$
\begin{aligned}
{ }_{t} p_{x y} & ={ }_{t} p_{x} \times{ }_{t} p_{y} \\
& =\frac{l_{x+t}}{l_{x}} \times \frac{l_{y+t}}{l_{y}}=\frac{l_{x y+t}}{l_{x y}}
\end{aligned}
$$

Peluang dua orang berusia $x$ dan $y$ yang meninggal dalam jangka waktu $t$ tahun dinotasikan dengan ${ }_{t} q_{x y}$, (Futami [4]) dan dirumuskan sebagai berikut:

$$
\begin{array}{r}
{ }_{t} q_{x y}=1-{ }_{t} p_{x y} \\
=\frac{l_{x y}-l_{x y+t}}{l_{x y}}
\end{array}
$$

Anuitas awal pada anuitas yang ditunda dengan jangka waktu penundaan $t$ tahun, (Futami [3]) dirumuskan sebagai berikut:

$$
{ }_{t} \mid \ddot{a}_{x}=\frac{N_{x+t}}{D_{x}}
$$

Nilai sekarang anuitas awal dari anuitas hidup berjangka joint life apabila $x$ dan $y$ tetap hidup, dalam (Futami [4]) dirumuskan sebagai berikut:

$$
\begin{gathered}
\ddot{a}_{x y: t\rceil}=1+v \cdot p_{x y}+v^{2} \cdot{ }_{2} p_{x y}+\cdots \\
+v^{t-1} \cdot{ }_{t-1} p_{x y} \\
=\sum_{m=0}^{t-1} v^{m}{ }_{m} p_{x y}
\end{gathered}
$$

Premi tunggal pure endowment joint life untuk peserta yang berusia $x$ tahun dan $y$ tahun, dengan jangka waktu tertanggung $t$ tahun dan besar uang pertanggungan adalah Rp. 1, dalam (Futami [4]) dirumuskan sebagai berikut:

$$
A_{x y: t\rceil}{ }^{1}=v^{t} \frac{l_{x y+t}}{l_{x y}}=v^{t}{ }_{t} p_{x y}
$$

Premi tunggal asuransi berjangka joint life menurut (Matvejevs \& Matvejevs [5]) dirumuskan sebagai berikut:

$A_{x y: t\rceil}^{1}=\sum_{m=0}^{t-1} v^{m+1}\left({ }_{m} p_{x y}-{ }_{m+1} p_{x y}\right)$.

Premi tunggal anuitas menaik pada asuransi joint life dalam (Futami [4]) dirumuskan sebagai berikut:

$$
(I A)_{x y: t]}^{1}=\sum_{m=0}^{t-1} m+1 v^{m+1}\left({ }_{m} p_{x y}-{ }_{m+1} p_{x y}\right)^{(7)}
$$

Menurut (Matvejevs \& Matvejevs [5]) nilai tunai dari pendapatan premi dan nilai tunai dari benefit yang dibayarkan oleh pihak penanggung dapat dirumuskan sebagai berikut:

Nilai tunai dari pendapatan premi tahunan konstan pada joint life dapat dinyatakan sebagai

P. $\left(1+v \cdot p_{x y}+v^{2} \cdot{ }_{2} p_{x y}+\cdots+v^{t-1} \cdot{ }_{t-1} p_{x y}\right)=P . \ddot{a}_{x y: t}$

Nilai tunai dari benefit yang dibayarkan oleh pihak penanggung dapat dinyatakan sebagai

$$
\begin{aligned}
& Q . v^{t} \cdot{ }_{t} p_{x y}+R_{x} \sum_{m=0}^{t-1} \sum_{k=t}^{\infty} v^{k}{ }_{k} p_{x m} \mid q_{x} \\
& +R_{y} \sum_{k=0}^{t-1} \sum_{m=t}^{\infty} v^{m}{ }_{m} p_{y}\left|{ }_{k}\right| q_{x}+P .(I A)_{x y: t]}^{1} \\
& =Q \cdot A_{x y: \frac{1}{t} \mid}+R_{x \cdot} \cdot{ }_{t}\left|\ddot{a}_{x \cdot} \cdot{ }_{t} q_{y}+R_{y \cdot t}\right| \ddot{a}_{y} \cdot{ }_{t} q_{x} \\
& +P .(I A)_{x y: t]}^{1}
\end{aligned}
$$

Dengan menggunakan prinsip ekivalensi, besar preminya adalah

$$
\begin{aligned}
P \cdot \ddot{a}_{x y: t]}=Q \cdot A_{x y: t]}+\frac{1}{+}+R_{x \cdot t}\left|\ddot{a}_{x \cdot t} q_{y}+R_{y} \cdot{ }_{t}\right| \ddot{a}_{y^{*} \cdot{ }_{t}} q_{x} \\
+P \cdot(I A)_{x y: t]}^{1}
\end{aligned}
$$


sehingga besarnya premi tahunan yang harus dibayarkan oleh peserta asuransi adalah

$P=\frac{Q \cdot A_{x y: n}+R_{x \cdot n}\left|\ddot{a}_{x \cdot n} q_{y}+R_{y \cdot n}\right| \ddot{a}_{y^{*} n} q_{x}}{\ddot{a}_{x y: n \mid}-(I A)_{x y: n \mid}^{1}}$.

\section{METODE PENELITIAN}

Data yang digunakan pada penelitian ini adalah data sekunder yang bersumber dari Matvejevs \& Matvejevs [5]. Data sekunder yang digunakan adalah usia awal peserta pada saat mengikuti kontrak asuransi joint life, masa pertanggungan asuransi, tingkat bunga, formula premi tahunan konstan asuransi joint life. Pada penelitian ini juga menggunakan Tabel Mortalitas Indonesia (TMI) 2011.

Langkah-langkah dalam proses penelitian ini adalah: (1) Menentukan formula cadangan premi tahunan pada asuransi joint life dengan perhitungan cadangan premi secara retrospektif; (2) Menghitung nilai dari tabel mortalitas joint life berdasarkan Tabel Mortalitas Indonesia (TMI) 2011; (3) Menghitung nilai tunai pembayaran untuk tingkat bunga; (4) Menghitung nilai dari tabel komutasi tunggal; (5) Menghitung nilai anuitas awal dari anuitas hidup yang ditunda; (6) Menghitung nilai premi tunggal pure endowment, nilai premi tunggal asuransi berjangka joint life, nilai premi tunggal anuitas menaik pada asuransi joint life. Menghitung nilai premi tahunan konstan pada asuransi joint life; (8) Menghitung nilai cadangan premi tahunan pada asuransi joint life menggunakan formula yang telah didapat pada langkah pertama.

\section{HASIL DAN PEMBAHASAN}

\subsection{Formula Cadangan Premi Tahunan Asuransi Joint Life}

Kontrak asuransi joint life ini melibatkan pasangan suami-istri dengan usia berturutturut $x$ tahun dan $y$ tahun dengan uang pertanggungan sebagai berikut: (a) Apabila kedua peserta asuransi joint life ( $x$ dan $y$ ) masih hidup sampai kontrak berakhir maka akan diberikan uang pertanggungan sebesar $Q$ dan kontrak asuransi berakhir; (b) Apabila salah satu peserta asuransi joint life meninggal dunia sebelum masa kontrak berakhir, misalkan $x$ meninggal, maka pembayaran premi dihentikan dan pada akhir tahun kematian dari $x$ akan diberikan uang sejumlah premi yang telah dibayarkan kepada pasangannya yang masih hidup. Apabila pasangannya yaitu $y$ masih tetap hidup diakhir kontrak, maka $y$ akan diberikan uang sebesar $R_{y}$ setiap tahunnya selama seumur hidup. Begitu juga sebaliknya, apabila $y$ meninggal dunia maka $x$ yang akan diberikan uang sebesar $R_{x}$ setiap tahunnya selama seumur hidup. Namun apabila pasangannya juga meninggal sebelum masa kontrak berakhir maka tidak ada pembayaran uang pertanggungan lagi; (c) Apabila $x$ dan $y$ keduaduanya meninggal ditahun yang sama sebelum kontrak berakhir maka uang pertanggungan sejumlah premi yang telah dibayarkan akan diberikan kepada ahli warisnya dan kontrak asuransi berakhir.

Berdasarkan kontrak asuransi tersebut maka diperoleh formula cadangan premi untuk asuransi joint life dengan metode perhitungan secara retrospektif adalah sebagai berikut:

Cadangan premi akhir tahun pertama adalah sebagai berikut:

$$
{ }_{1} V=\frac{P \cdot l_{x y}(1+i)-P\left(l_{x y}-l_{x+1, y+1}\right)}{l_{x+1, y+1}+l_{x+1}\left(l_{y}-l_{y+1}\right)+l_{y+1}\left(l_{x}-l_{x+1}\right)}
$$

dengan $P . l_{x y}(1+i)$ merupakan premi bersih tahunan yang dibayarkan pada permulaan tahun pertama yang dibungakan selama setahun kemudian dikurangi dengan $P\left(l_{x y}-\right.$ $\left.l_{x+1, y+1}\right)$ yang merupakan uang pertanggungan yang dibayarkan pada akhir tahun pertama.

Selanjutnya untuk lebih memudahkan penulisannya, dimisalkan $k_{s}=l_{x+s, y+s}+$ $l_{x+s}\left(l_{y}-l_{y+s}\right)+l_{y+s}\left(l_{x}-l_{x+s}\right) \quad$ dengan $s=1,2,3, \ldots, t$ dan $t$ merupakan lamanya masa pembayaran premi atau lamanya kontrak asuransi sehingga cadangan premi akhir tahun kedua adalah sebagai berikut: 
${ }_{2} V=\frac{\left(k_{1} \cdot{ }_{1} V+P \cdot l_{x+1, y+1}\right)(1+i)-2 P\left(l_{x+1, y+1}-l_{x+2, y+2}\right)}{k_{2}}$

dengan $k_{1} \cdot{ }_{1} V \quad$ merupakan seluruh dana yang berasal dari tahun pertama kemudian ditambahkan dengan premi pada tahun kedua yaitu $P . l_{x+1, y+1}$. Keduanya kemudian dibungakan selama setahun lalu dikurangi dengan $2 P\left(l_{x+1, y+1}-l_{x+2, y+2}\right)$ yang merupakan uang pertanggungan yang dibayarkan pada akhir tahun kedua. Selisih tersebut kemudian dibagi dengan $k_{2}$. Selanjutnya cadangan akhir tahun ketiga sampai akhir tahun ke- $t$ menggunakan formula yang sama seperti cadangan akhir kedua.

$$
\begin{aligned}
& { }_{3} V=\frac{\left(k_{2 \cdot}{ }_{2} V+P \cdot l_{x+2, y+2}\right)(1+i)-3 P\left(l_{x+2, y+2}-l_{x+3, y+3}\right)}{k_{3}} \\
& \quad \vdots \\
& { }_{t} V \\
& =\frac{\left(k_{t-1 \cdot t-1} V+P \cdot l_{x+t-1, y+t-1}\right)(1+i)-t P\left(l_{x+t-1, y+t-1}-l_{x+t, y+t}\right)}{k_{t}}
\end{aligned}
$$

Selanjutnya cadangan premi akhir tahun ke- $t+1$ berbeda dengan cadangan premi akhir tahun ke-t karena pada tahun ke- $t+1$ sudah tidak ada pembayaran premi lagi.

Dimisalkan $u_{j}=l_{x+j}\left(l_{y}-l_{y+t}\right)+l_{y+j}\left(l_{x}-\right.$ $l_{x+t}$ ) dengan $j=t+1, t+2, \ldots$, sehingga cadangan akhir tahun ke- $t+1$ adalah sebagai berikut

$$
\begin{array}{r}
{ }_{t+1} V=\frac{\left(k_{t} \cdot{ }_{t} V\right)(1+i)}{u_{t+1}}-\frac{Q\left(l_{x+t, y+t}\right)(1+i)}{u_{t+1}}- \\
\begin{array}{r}
\frac{R_{x}\left(l_{x+t}\right)\left(l_{y}-l_{y+t}\right)(1+i)}{u_{t+1}} \\
\quad-\frac{R_{y}\left(l_{y+t}\right)\left(l_{x}-l_{x+t}\right)(1+i)}{u_{t+1}}
\end{array}
\end{array}
$$

dengan $\left(k_{t} \cdot{ }_{t} V\right)(1+i)$ seluruh dana yang berasal dari tahun ke-t kemudian dibungakan selama setahun lalu dikurangi dengan $Q\left(l_{x+t, y+t}\right)(1+i)$ yaitu uang pertanggungan yang diberikan apabila $x$ dan $y$ masih tetap hidup sampai akhir tahun ke- $t$ yang dibungakan selama setahun. $R_{x}\left(l_{x+t}\right)\left(l_{y}-\right.$ $\left.l_{y+t}\right)(1+i)$ yaitu uang pertanggungan yang diberikan apabila $y$ meninggal sebelum akhir tahun ke- $t$ dan $x$ masih tetap hidup sampai akhir tahun ke- $t$ lalu dibungakan selama setahun, $R_{y}\left(l_{y+t}\right)\left(l_{x}-l_{x+t}\right)(1+i)$ yaitu uang pertanggungan yang diberikan apabila $x$ meninggal sebelum akhir tahun ke- $t$ dan $y$ masih tetap hidup sampai akhir tahun ke- $t$ lalu dibungakan selama setahun. Selisih tersebut kemudian dibagi dengan $u_{t+1}$.

Selanjutnya cadangan premi akhir tahun ke- $t+2$ adalah sebagai berikut:

$$
\begin{aligned}
{ }_{t+2} V= & \frac{\left(u_{t+1 \cdot t+1} V\right)(1+i)}{u_{t+2}}-\frac{R_{x}\left(l_{x+t+1}\right)\left(l_{y}-l_{y+t}\right)(1+i)}{u_{t+2}}- \\
& \frac{R_{y}\left(l_{y+t+1}\right)\left(l_{x}-l_{x+t}\right)(1+i)}{u_{t+2}}
\end{aligned}
$$

dengan $\left(u_{t+1} \cdot{ }_{t} V\right)(1+i)$ merupakan seluruh dana yang berasal dari tahun ke- $t+1$ yang dibungakan selama setahun lalu dikurangi dengan $R_{x}\left(l_{x+t}\right)\left(l_{y}-l_{y+t}\right)(1+i)$ yaitu uang pertanggungan yang diberikan apabila $y$ meninggal sebelum akhir tahun ke-t dan $x$ masih tetap hidup sampai akhir tahun ke- $t+1$ lalu dibungakan selama setahun, dan $R_{y}\left(l_{y+t}\right)\left(l_{x}-l_{x+t}\right)(1+i) \quad$ yaitu uang pertanggungan yang diberikan apabila $x$ meninggal sebelum akhir tahun ke- $t$ dan $y$ masih tetap hidup sampai akhir tahun ke- $t+1$ lalu dibungakan selama setahun. Selisih tersebut kemudian dibagi dengan $u_{t+2}$.

Cadangan premi akhir tahun ke- $t+3$ dan seterusnya sampai seumur hidup dicari dengan menggunakan formula yang sama seperti pada cadangan premi akhir tahun ke- $t+2$.

\subsection{Contoh Kasus}

Usia peserta mulai mengikuti asuransi dalam kasus ini yaitu usia suami $(\boldsymbol{x})$ adalah 50 tahun sedangkan untuk usia istri $(\boldsymbol{y})$ adalah 45 tahun dengan masa pembayaran premi adalah $\boldsymbol{t}=\mathbf{1 0}$ tahun. Tingkat suku bunga yang digunakan dalam kasus ini adalah konstan yaitu sebesar $5 \%$.

Rincian uang pertanggungan yang diberikan perusahaan asuransi kepada peserta asuransi joint life adalah sebagai berikut: (a) Apabila kedua peserta asuransi joint life ( $x$ dan $y$ ) masih hidup sampai kontrak berakhir maka akan diberikan uang pertanggungan sebesar Rp.1 $(Q=1)$ dan kontrak asuransi berakhir; (b) Apabila salah satu peserta asuransi joint life meninggal dunia sebelum masa kontrak berakhir, misalkan $x$ meninggal, maka 
pembayaran premi dihentikan dan pada akhir tahun kematian dari $x$ akan diberikan uang sejumlah premi yang telah dibayarkan kepada pasanganya yang masih hidup. Apabila pasangannya yaitu $y$ masih tetap hidup diakhir kontrak, maka $y$ akan diberikan uang sebesar Rp.1 $\quad\left(R_{y}=1\right)$ setiap tahunnya selama seumur hidup. Begitu juga sebaliknya, apabila $y$ meninggal dunia maka $x$ yang akan diberikan uang sebesar Rp.1 $\left(R_{x}=1\right)$ setiap tahunnya selama seumur hidup. Namun apabila pasangannya juga meninggal sebelum masa kontrak berakhir maka tidak ada pembayaran uang pertanggungan lagi. (c) Apabila $x$ dan $y$ kedua-duanya meninggal ditahun yang sama sebelum kontrak berakhir maka uang pertanggungan sejumlah premi yang telah dibayarkan akan diberikan kepada ahli warisnya dan kontrak asuransi berakhir.

Berdasarkan kontrak asuransi tersebut dan berdasarkan persamaan (10) maka diperoleh nilai premi tahunan konstan untuk asuransi joint life adalah sebagai berikut:

$P=\frac{Q \cdot A_{x y: t\rceil}+R_{x \cdot t}\left|\ddot{a}_{x \cdot{ }_{t}} q_{y}+R_{y \cdot t}\right| \ddot{a}_{y \cdot{ }_{t}} q_{x}}{\ddot{a}_{x y: t\rceil}-(I A)_{x y: t]}^{1}}$

$=\frac{0,54106+(6,721302 \times 0,03314)+(8,659537 \times 0,08846)}{7,78135-0,51642}$ $7,78135-0,51642$

$=0,21058$

Selanjutnya nilai cadangan premi untuk asuransi joint life dengan menggunakan formula yang telah diperoleh sebelumnya dapat dilihat pada Tabel 3.1.

Dapat dilihat pada Tabel 3.1 hasil perhitungan cadangan premi pada asuransi joint life dengan menggunakan perhitungan secara retrospektif untuk usia peserta $x=50$ dan $y=45$ diperoleh cadangan premi akhir tahun ke-1 sampai dengan akhir tahun ke-11 mengalami peningkatan setiap tahunnya yang disebabkan karena uang yang masuk ke perusahaan asuransi dari pembayaran premi sangat besar dan terus meningkat setiap tahunnya jauh melampaui jumlah uang pertanggungan yang harus dibayarkan sehingga cadangan premi yang diperoleh juga terus meningkat setiap tahunnya.

Tabel 3.1 Nilai Cadangan Premi Asuransi Jiwa Joint Life untuk $x=50$ dan $y=45$

\begin{tabular}{|c|c|c|c|}
\hline $\begin{array}{l}\text { Jangka } \\
\text { Waktu } \\
\text { (w) }\end{array}$ & ${ }_{w} V$ & $\begin{array}{c}\text { Jangka } \\
\text { Waktu } \\
\text { (w) }\end{array}$ & ${ }_{w} V$ \\
\hline 1 & 0.21957 & 34 & 7.12545 \\
\hline 2 & 0.44660 & 35 & 6.84150 \\
\hline 3 & 0.68084 & 36 & 6.55873 \\
\hline 4 & 0.92203 & 37 & 6.28404 \\
\hline 5 & 1.16990 & 38 & 6.01835 \\
\hline 6 & 1.42415 & 39 & 5.75848 \\
\hline 7 & 1.68452 & 40 & 5.50432 \\
\hline 8 & 1.95068 & 41 & 5.25641 \\
\hline 9 & 2.22234 & 42 & 5.00598 \\
\hline 10 & 2.49927 & 43 & 4.76813 \\
\hline 11 & 13.67372 & 44 & 4.54290 \\
\hline 12 & 13.42691 & 45 & 4.33150 \\
\hline 13 & 13.17482 & 46 & 4.12583 \\
\hline 14 & 12.91677 & 47 & 3.89479 \\
\hline 15 & 12.65248 & 48 & 3.65545 \\
\hline 16 & 12.38185 & 49 & 3.42292 \\
\hline 17 & 12.10511 & 50 & 3.20895 \\
\hline 18 & 11.82236 & 51 & 3.03087 \\
\hline 19 & 11.53587 & 52 & 2.88485 \\
\hline 20 & 11.24550 & 53 & 2.77982 \\
\hline 21 & 10.95207 & 54 & 2.64108 \\
\hline 22 & 10.65609 & 55 & 2.49038 \\
\hline 23 & 10.35973 & 56 & 2.34529 \\
\hline 24 & 10.06286 & 57 & 2.20507 \\
\hline 25 & 9.76568 & 58 & 2.07042 \\
\hline 26 & 9.46727 & 59 & 1.94229 \\
\hline 27 & 9.16836 & 60 & 1.82246 \\
\hline 28 & 8.87004 & 61 & 1.71290 \\
\hline 29 & 8.57319 & 62 & 1.61176 \\
\hline 30 & 8.27878 & 63 & 1.51589 \\
\hline 31 & 7.98680 & 64 & 1.41525 \\
\hline 32 & 7.69779 & 65 & 1.28223 \\
\hline 33 & 7.41078 & 66 & 1.00000 \\
\hline
\end{tabular}

Selanjutnya nilai cadangan premi dari tahun ke-12 dan seterusnya mengalami penurunan yang disebabkan karena dari tahun ke-11 sudah tidak ada lagi pembayaran premi sehingga tidak ada lagi uang yang masuk ke perusahaan asuransi sedangkan perusahaan asuransi harus tetap melakukan pembayaran uang pertanggungan setiap tahunnya sehingga cadangan premi yang terdapat diperusahaan asuransi akan terus menurun setiap tahunnya.

\section{KESIMPULAN DAN SARAN}

Berdasarkan hasil dan pembahasan yang telah dijelaskan, maka dapat disimpulkan bahwa rumusan/formula cadangan premi 
untuk asuransi joint life dengan perhitungan secara retrospektif adalah sebagai berikut:

${ }_{1} V=\frac{P . l_{x y}(1+i)-P\left(l_{x y}-l_{x+1, y+1}\right)}{l_{x+1, y+1}+l_{x+1}\left(l_{y}-l_{y+1}\right)+l_{y+1}\left(l_{x}-l_{x+1}\right)}$

Dimisalkan $\quad k_{s}=l_{x+s, y+s}+l_{x+s}\left(l_{y}-l_{y+s}\right)+$ $l_{y+s}\left(l_{x}-l_{x+s}\right)$ dengan $s=1,2,3, \ldots, t$ dan $t$ merupakan lamanya masa pembayaran premi atau lamanya kontrak asuransi sehingga cadangan premi akhir tahun kedua sampai akhir tahun ke- $t$ adalah sebagai berikut:

$$
\begin{aligned}
{ }_{m} V= & \frac{\left(k_{m-1 \cdot m-1} V+P \cdot l_{x+m-1, y+m-1}\right)(1+i)}{k_{m}}- \\
& \frac{m P\left(l_{x+m-1, y+m-1}-l_{x+m, y+m}\right)}{k_{m}}
\end{aligned}
$$

dengan $m=2,3, \ldots, t$. Selanjutnya dimisalkan $u_{j}=l_{x+j}\left(l_{y}-l_{y+t}\right)+l_{y+j}\left(l_{x}-l_{x+t}\right) \quad$ dengan $j=t+1, t+2, \ldots$, sehingga cadangan akhir tahun ke- $t+1$ sampai seterusnya adalah sebagai berikut:

$$
\begin{array}{r}
{ }_{t+1} V=\frac{\left(k_{t} \cdot{ }_{t} V\right)(1+i)}{u_{t+1}}-\frac{Q\left(l_{x+t, y+t}\right)(1+i)}{u_{t+1}}- \\
\frac{R_{x}\left(l_{x+t}\right)\left(l_{y}-l_{y+t}\right)(1+i)}{u_{t+1}} \\
\quad-\frac{R_{y}\left(l_{y+t}\right)\left(l_{x}-l_{x+t}\right)(1+i)}{u_{t+1}}
\end{array}
$$

$$
\begin{aligned}
{ }_{t+2} V= & \frac{\left(u_{t+1 \cdot t+1} V\right)(1+i)}{u_{t+2}}-\frac{R_{x}\left(l_{x+t+1}\right)\left(l_{y}-l_{y+t}\right)(1+i)}{u_{t+2}}- \\
& \frac{R_{y}\left(l_{y+t+1}\right)\left(l_{x}-l_{x+t}\right)(1+i)}{u_{t+2}}
\end{aligned}
$$

dan seterusnya

Berdasarkan formula cadangan premi tersebut serta untuk kasus usia awal peserta laki-laki 50 tahun dan perempuan 45 tahun dan lama pembayaran premi 10 tahun, diperoleh nilai cadangan premi akhir tahun ke-1 sampai akhir tahun ke-11 mengalami peningkatan setiap tahunnya, sedangkan nilai cadangan premi dari akhir tahun ke-12 dan seterusnya sampai seumur hidup mengalami penurunan.

Pada penelitian ini, penulis hanya dapat meneliti bagaimana cara menentukan formula dari cadangan premi tahunan pada asuransi joint life menggunakan metode perhitungan secara retrospektif dengan tingkat suku bunga konstan. Tidak menutup kemungkinan untuk peneliti selanjutnya dapat menggunakan tingkat suku bunga yang tidak konstan dan menggunakan metode perhitungan cadangan premi bersih lainnya seperti metode perhitungan secara prospektif.

\section{DAFTAR PUSTAKA}

[1] Bowers NL, Gerber HU, Hickman JC, Jones DA, dan Nesbitt CJ. 1997. Actuarial Mathematics. $2^{\text {nd }}$ ed. Schaumburg : The Society of Actuaries.

[2] Destriani, Satyahadewi, N. \& Mara, M.N., 2014. Penentuan Nilai Cadangan Prospektif pada Asuransi Jiwa Seumur Hidup Menggunakan Metode New Jersey. Buletin Ilmiah Mat.Stat dan Terapannya (BIMASTER), 03, pp.7-12.

[3] Futami, T., 1993. Matematika Asuransi Jiwa Bagian I. Herliyanto G, penerjemah. Tokyo (JP): Oriental Life Insurance Cultural Development Center. Terjemahan dari: Seime Hoken Sugaku Gekan ("92 Revision).

[4] ,1994. Matematika Asuransi

Jiwa Bagian 2. Herliyanto G, penerjemah. Tokyo (JP): Oriental Life Insurance Cultural Development Center. Terjemahan dari: Seime Hoken Sugaku Gekan ("92 Revision).

[5] Matvejevs, A. \& Matvejevs, A., 2001. Insurance Models for Joint Life and Last Survivor Benefit. Informatica, 12(4), pp.547-58. 